\title{
Risk Factors for Borderline Personality Disorder in Treatment Seeking Patients with a Substance Use Disorder: An International Multicenter Study
}

\author{
Manuela Wapp ${ }^{a, b}$ Geurt van de Glind ${ }^{c, d}$ Katelijne van Emmerik-van Oortmerssen ${ }^{d, e}$ \\ Geert Dom $^{f}$ Sofie Verspreet ${ }^{f}$ Pieter Jan Carpentierg Josep Antoni Ramos-Quirogah \\ Arvid Skutle $^{\mathrm{i}} \quad$ Eli-Torlid Bu $^{\mathrm{i}}$ Johan Franck ${ }^{j} \quad$ Maija Konstenius $^{j} \quad$ Sharlene Kaye $^{\mathrm{k}}$

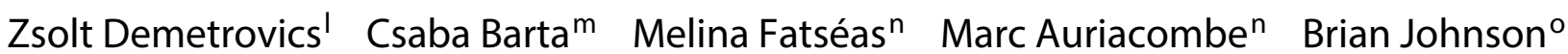 \\ Stephen V. Faraone ${ }^{0, p} \quad$ Frances R. Levin $^{q}$ Steve Allsop ${ }^{r} \quad$ Susan Carruthers $^{r}$ \\ Robert A. Schoevers ${ }^{s}$ Maarten W.J. Koeter ${ }^{d}$ Wim van den Brink ${ }^{d} \quad$ Franz Moggia,t
} IASP Research Group

\begin{abstract}
a University Hospital of Psychiatry, and ${ }^{b}$ Center for Cognition, Learning and Memory, University of Bern, Bern, Switzerland; ${ }^{\mathrm{C}}$ Trimbos Institute and ICASA Foundation, Utrecht, and d Amsterdam Institute for Addiction Research, Department of Psychiatry, Academic Medical Center, University of Amsterdam, and ${ }^{\mathrm{e}}$ The Netherlands Arkin, Amsterdam, The Netherlands; ${ }^{\mathrm{f}}$ Collaborative Antwerp Psychiatry Research Institute (CAPRI, UA), PC Alexian Brothers, Boechout, Belgium; ${ }^{9}$ Reinier van Arkel Groep, 's-Hertogenbosch, The Netherlands; ${ }^{\mathrm{h}}$ Servei de Psiquiatria, Hospital Universitari Vall d'Hebron, CIBERSAM, Department of Psychiatry, Universitat Autònoma de Barcelona, Barcelona, Spain; 'Bergen Clinics Foundation, Bergen, Norway; 'Department of Clinical Neuroscience,

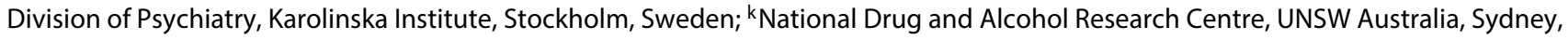
N.S.W., Australia; 'Institute of Psychology, Eötvös Loránd University, and ${ }^{\mathrm{m}}$ Institute of Medical Chemistry, Molecular Biology and Pathobiochemistry, Semmelweis University, Budapest, Hungary; ${ }^{n}$ Laboratoire de Psychiatrie, Département d'Addictologie, Université de Bordeaux, Bordeaux, France; Departments of ${ }^{\circ}$ Psychiatry and ${ }^{\mathrm{P}}$ Neuroscience and Physiology, SUNY Upstate Medical University, Syracuse, N.Y., and ${ }^{9}$ Columbia University, The New York State Psychiatric Institute, New York, N.Y., USA; ${ }^{r}$ National Drug Research Institute, Curtin University of Technology, Perth, W.A., Australia; ${ }^{5}$ Department of Psychiatry, University Medical Center Groningen, University of Groningen, Groningen, The Netherlands; ${ }^{\mathrm{t}}$ Department of Psychology, University of Fribourg, Fribourg, Switzerland
\end{abstract}

\section{Key Words}

Risk factors · Substance use disorder $\cdot$ Borderline personality disorder $\cdot$ Comorbidity

The IASP Research Group also includes: Eva Karin Løvaas, Kari Lossius, Anneke van Wamel, Geert Bosma, David Hay, Sara Wallhed, Marion Malivert, Romain Debrabant, Therese Dahl, Miguel Casas, Carlos Roncero, Constanza Daigre, Rutger-Jan van der Gaag, Atul Beniwal, Máté Kapitány-Fövény, Louisa Degenhardt, Joanne Cassar, Jesse Young and Merete Möller.

\section{KARGER 125}

2015 S. Karger AG, Base

$1022-6877 / 15 / 0214-0188 \$ 39.50 / 0$

E-Mail karger@karger.com

www.karger.com/ear

\begin{abstract}
Prof. Franz Moggi, PhD, EMBA

University Hospital of Psychiatry, University of Bern Bolligenstrasse 111 CH-3000 Bern 60 (Switzerland)

E-Mail moggi@puk.unibe.ch
\end{abstract}

Borderline personality disorder (BPD) and substance use disorders (SUDs) often co-occur, partly because they share risk factors. In this international multicenter study, risk factors for BPD were examined for SUD patients. In total, 1,205 patients were comprehensively examined by standardized interviews and questionnaires on psychiatric diagnosis and risk factors, and it was found that 1,033 (85.7\%) had SUDs without BPD (SUD) and 172 (14.3\%) had SUD with BPD (SUD + $B P D)$. SUD + BPD patients were significantly younger, more 
often females and more often diagnosed with comorbid adult attention deficit/hyperactivity disorder. SUD + BPD patients did not differ from SUD patients on most risk factors typical for SUD such as maternal use of drugs during pregnancy or parents having any SUD. However, SUD + BPD patients did have a higher risk of having experienced emotional and physical abuse, neglect, or family violence in childhood compared to SUD patients, suggesting that child abuse and family violence are BPD-specific risk factors in patients with SUDs.

(c) 2015 S. Karger AG, Basel

\section{Introduction}

Substance use disorders (SUDs) such as alcohol and/ or drug use disorders are major public health problems that have serious biological, psychological, and social consequences [1]. Moreover, individuals with SUDs have elevated rates of a host of psychiatric disorders, including various personality disorders (PDs) [2].

Psychiatric disorders among patients with SUDs are well recognized and of great clinical and public health interest. These so-called 'dual disorder' patients have more inpatient treatment and a higher prevalence of suicide, social problems and medical conditions compared to those who have only one psychiatric disorder [3].

There is a strong link between PDs and SUDs, borderline personality disorder (BPD) in particular [4]. BPD is a common mental disorder with severe functional impairment characterized by interpersonal dysfunction, disturbed self-image, emotional instability and impulsivity. In treatment-seeking psychiatric patients, $10 \%$ of outpatients and $15-25 \%$ of inpatients have BPD [5].

Numerous studies have investigated the comorbidity of BPD and SUDs. Patients with BPD or antisocial PD have the greatest co-occurrence with SUD in both the general population and in clinical settings $[4,6,7]$. In a large community sample of nearly 35,000 participants, $2.7 \%$ had BPD. Almost $80 \%$ of those were diagnosed with a lifetime SUD [8]. Cross-sectional clinical studies found that $23-84 \%$ of BPD patients (BPD as the index group) met criteria for SUDs [9]. Conversely, treatment-seeking SUD patients (SUD as the index group) have high rates of $\mathrm{PD}$, among those 5-22\% with BPD [10]. In a clinical sample, Morgenstern et al. [11] found a BPD prevalence of $22.4 \%$ for patients with alcohol use disorder. Based on the findings of these last two studies, up to one fifth of treatment-seeking SUD patients may suffer from a BPD in addition to a SUD.

Risk Factors for BPD in SUD
Risk factors are correlates that at least precede and change the occurrence of a disorder but are not its concomitant or consequence. Risk factors are not necessarily causal but a variable or fixed marker of a disorder [12]. For example, risk factors for SUD include alcohol use by the mother during pregnancy or a family history of SUD [13-15].

Risk factors for BPD are often explained within a biopsychosocial model; genetic factors as well as adverse childhood events influence biological and psychosocial factors which in turn increase the risk of BPD [5]. Family studies have shown an elevated frequency of mood disorders among parents of the BPD patients [4]. SUD and BPD also share certain risk factors. For example, twin studies have shown that unique environmental factors increase the risk for both BPD and SUD [16]. Childhood sexual, physical and emotional abuse, violence within the family, or neglect are risk factors for BPD [17-19] as well as for SUDs [1, 13, 15, 20].

The aim of this large international multicenter study is to examine risk factors such as family history of SUD and mood disorders, childhood abuse, and family violence comparing SUD patients with BPD (SUD + BPD) with patients without BPD comorbidity (SUD). We controlled for age, gender and attention deficit/hyperactivity disorder (ADHD) to estimate the contribution of each risk factor. ADHD is generally associated with an elevated risk of having a psychiatric disorder, including a BPD diagnosis [21]. In a former data analysis of this large SUD treatment-seeking patient sample, a higher risk for BPD was found for SUD patients with ADHD compared to patients without ADHD [22].

To our knowledge, this is the first study in a large patient sample investigating the contribution of risk factors of BPD in patients with SUD + BPD compared to SUD patients.

\section{Methods}

\section{Design and Procedure}

The study was conducted by the International Collaboration on ADHD and Substance Abuse [23] and was part of the International ADHD in Substance Use Disorder Prevalence (IASP) study. The IASP is an international, multicenter, cross-sectional study consisting of a screening stage for ADHD and a diagnostic stage with a full assessment of various psychiatric disorders, including BPD and SUD. Ten countries (Australia, Belgium, France, Hungary, Norway, Spain, Sweden, Switzerland, the Netherlands and the USA) with 47 SUD treatment centers participated in the screening stage. France, Hungary, Norway, Spain, Sweden, Switzerland and the Netherlands also participated in the full assessment, which

Eur Addict Res 2015;21:188-194 
took place within a few weeks after the screening stage. Treatments varied from outpatient to inpatient treatment settings and included treatment facilities for alcohol use disorders, drug use disorders and mixed SUDs. For a detailed description of the background, the study population and the screening results, see van de Glind et al. [24]. The regional ethics committees of all participating countries and centers approved the IASP study. Written informed consent was obtained from all patients prior to study inclusion. Patients did not receive financial compensation, except for those in Australia, where patients received AUD 20 compensation for associated costs.

\section{Patients}

Of the 3,558 SUD treatment-seeking patients, 1,205 agreed to participate and completed the full assessment to diagnose psychiatric disorders (drop-out rate is discussed in another publication [24]). Of these 1,205 patients who were comprehensively assessed, 695 (57.7\%) had SUD only and 338 (28.0\%) had SUD and psychiatric comorbidities other than BPD (e.g. mood disorders, antisocial PD or ADHD). In addition, 172 (14.3\%) had comorbid BPD, including $50(4.0 \%)$ with BPD comorbidity only. Therefore, the present study included two subsamples; 1,205 patients including 1,033 SUD patients with or without comorbidity other than BPD, and 172 SUD + BPD with or without other current psychiatric disorders.

\section{Measures}

For this study, we used the questionnaires and semistructured interviews in the full assessment stage of the IASP, all administered by trained clinicians. The borderline module of the Structured Clinical Interview for DSM-IV personality disorders (SCID II) [25, 26] was conducted to assess BPD and the Mini International Neuropsychiatric Interview (M.I.N.I.) Plus version 5.0.0 [27] was used to assess prior and current episodes of SUD, mood disorders (e.g. major depressive disorder, bipolar disorder) and antisocial personality disorder according to the DSM-IV criteria. Risk factors were evaluated with the Conners' Adult ADHD Diagnostic Interview for DSM-IV (CAADID) Part I [28], a questionnaire that was completed by the patient to assess information on developmental course and risk factors. The important risk factors for BPD and SUD assessed in this study are: mother used alcohol and/or other drugs during pregnancy, diagnosis of alcohol and/or other drug use disorders of mother and/or father, depression and/or bipolar disorders of mother and/or father, childhood abuse (e.g. sexual abuse, physical abuse and emotional abuse), physical and emotional neglect, and experience of violence within the family. The number of adverse childhood experiences (i.e. sexual abuse, physical abuse, emotional abuse, physical and emotional neglect and violence) was calculated by summing up these five risk factors.

\section{Statistical Analysis}

All statistical analyses were conducted using IBM SPSS Statistics 20.0 for Windows. All statistical tests were two-sided with a $5 \%$ significance level. To compare demographics and number of risk factors, independent $t$-tests and $\chi^{2}$-tests were used. The SUD group (index group) was compared with the SUD + BPD group by using hierarchic logistic regression analyses controlling for age, gender and ADHD. We additionally calculated the hierarchic logistic regression only with those SUD patients without any other comorbidities than $\mathrm{BPD}$ to control for other psychiatric comorbidities than BPD.
Table 1. Patients' characteristics

\begin{tabular}{lllll}
\hline & $\begin{array}{l}\text { Total } \\
(\mathrm{n}=1,205)\end{array}$ & $\begin{array}{l}\text { SUD } \\
(\mathrm{n}=1,033)\end{array}$ & $\begin{array}{l}\text { SUD + BPD } \\
(\mathrm{n}=172)\end{array}$ & $\chi^{2} / \mathrm{t}$ \\
\hline $\begin{array}{l}\text { Male } \\
\text { Age, years }\end{array}$ & 73.4 & 76.9 & 52.9 & $41.42^{* *}$ \\
$\begin{array}{l}\text { Social status } \\
\quad \text { Single }\end{array}$ & $54.0 \pm 11.2$ & $40.7 \pm 11.2$ & $35.6 \pm 9.9$ & $6.13^{* *}$ \\
$\quad$ Married & 17.8 & 53.4 & 60.1 & 5.18 \\
$\quad \begin{array}{l}\text { Divorced } \\
\text { Living with }\end{array}$ & 18.9 & 18.8 & 11.9 & \\
$\quad$ partner & 9.0 & 9.1 & 19.6 & \\
$\begin{array}{l}\text { Employed } \\
\text { Main substance }\end{array}$ & 30.9 & 32.3 & 22.1 & $6.43^{*}$ \\
$\quad$ Alcohol & 55.2 & 57.6 & 40.7 & $17.84^{* *}$ \\
$\quad$ Drugs & 44.8 & 42.4 & 59.3 & \\
\hline
\end{tabular}

Values represent $\%$ or means \pm SD. ${ }^{*} \mathrm{p}<0.05 ;{ }^{* *} \mathrm{p}<0.001$

\section{Results}

Among the overall sample of 1,205 patients, 647 were single, 212 were married, 225 were divorced, and 107 lived with a partner (from 14 patients we had no information about the social status). Social status did not differ between the two groups, but BPD + SUD patients were less often employed than SUD patients. SUD + BPD patients were significantly younger and more likely to be female than SUD patients. Hence, we controlled for age and gender in all other analyses (table 1). The two groups also differed in the rates of comorbidities: compared to SUD patients, SUD + BPD patients were more likely to meet the criteria for ADHD (29.7 vs. $11.3 \%, \chi^{2}=42.53$, $\mathrm{p}<0.001$ ), depression ( 39.0 vs. $16.7 \%, \chi^{2}=45.59, \mathrm{p}<$ $0.001)$ and bipolar disorders (25.9 vs. $3.0 \%, \chi^{2}=90.27, \mathrm{p}<$ $0.001)$. In contrast, patients with SUD had used alcohol significantly longer ( 14.4 vs. 10.6 years, $t=4.05, p<0.001$ ) and drank more alcohol per day before entering treatment than patients with SUD + BPD (8.4 vs. 5.4 standard drinks ( 1 standard drink is $10-12 \mathrm{~g}$ pure alcohol), $\mathrm{t}=3.24$, $\mathrm{p}<0.001)$. The primary substance of abuse was alcohol $(\mathrm{n}=665 ; 55.2 \%)$, followed by stimulants $(\mathrm{n}=180 ; 14.9 \%)$, cannabis $(\mathrm{n}=128 ; 10.6 \%)$, opiates $(\mathrm{n}=126 ; 10.5 \%)$ and other drugs $(\mathrm{n}=106 ; 8.8 \%)$. Compared to SUD patients, the primary substance of abuse in SUD + BPD patients was more likely to be illicit drugs and less likely to be alcohol.

Except for 'mother used alcohol during pregnancy', the two groups did not differ in SUD-specific risk factors. However, compared to SUD patients, SUD + BPD pa- 
Table 2. Logistic regressions with risk factors as the independent variable and SUD/SUD + BPD as the dependent variable controlled for age, gender and ADHD

\begin{tabular}{|c|c|c|c|c|c|}
\hline & $\begin{array}{l}\text { SUD } \\
(n=1,033)\end{array}$ & $\begin{array}{l}\text { SUD + BPD } \\
(n=172)\end{array}$ & $\mathrm{b}(\mathrm{SE})$ & Wald & OR $(95 \% \mathrm{CI})$ \\
\hline \multicolumn{6}{|l|}{ Patients' characteristics } \\
\hline Age & $40.7 \pm 11.2$ & $35.6 \pm 9.9$ & $-0.04(0.01)$ & $21.32 * *$ & $0.96(0.95-0.98)$ \\
\hline ADHD & 11.3 & 29.7 & $1.15(0.21)$ & $31.44^{* *}$ & $3.16(2.12-4.73)$ \\
\hline Parental alcohol use disorder & 26.3 & 28.5 & $-0.18(0.35)$ & 0.84 & $0.84(0.57-1.23)$ \\
\hline Parental drug use disorder & 5.8 & 8.7 & $0.01(0.33)$ & 0.01 & $1.00(0.53-1.91)$ \\
\hline Parental history of depression & 17.6 & 26.7 & $0.15(0.21)$ & 0.52 & $1.16(0.78-1.74)$ \\
\hline Parental history of bipolar disorder & 4.7 & 7.6 & $0.07(0.35)$ & 0.04 & $1.07(0.54-2.13)$ \\
\hline Childhood sexual abuse & 13.1 & 19.9 & $-0.06(0.24)$ & 0.05 & $0.95(0.56-1.52)$ \\
\hline Childhood physical abuse & 25.2 & 46.6 & $0.82(0.18)$ & $19.70^{* *}$ & $2.27(1.58-3.25)$ \\
\hline
\end{tabular}

Values represent $\%$ or means $\pm \mathrm{SD} .{ }^{*} \mathrm{p}<0.05 ;{ }^{* *} \mathrm{p}<0.001$

tients were significantly more likely to report the common risk factors of having experienced physical abuse, emotional abuse, neglect or family violence in childhood (table 2). Less than $1 \%$ of the mothers of the SUD patients $(0.8 \%)$ and SUD + BPD patients $(0.6 \%)$ consumed drugs during pregnancy; therefore, statistical analysis is not appropriate. While there was no overall difference between SUD and SUD + BPD patients with regard to the prevalence of childhood sexual abuse, there was a significant gender difference with more women reporting sexual abuse than men ( 28.1 vs. $\left.8.0 \%, \chi^{2}=77.9, \mathrm{p}<0.001\right)$.

In order to control for possible group differences regarding the presence of comorbid psychiatric disorders other than BPD, a comparison of risk factors between the 695 SUD-only and the 50 SUD + BPD-only patients was performed, again controlling for sex, age and ADHD. The results were similar to those from the comparison of the broader SUD and SUD + BPD groups: parental history of depression $(\mathrm{OR}=1.03, \mathrm{p}=0.94, \mathrm{CI}$ : $0.50-2.14)$, parental history of bipolar disorder $(\mathrm{OR}=0.83, \mathrm{p}=0.81$, CI: 0.18-3.80), number of adverse events $(\mathrm{OR}=0.78, \mathrm{p}=$ $0.01, \mathrm{CI}: 0.67-0.94)$, childhood sexual abuse $(\mathrm{OR}=1.12$, $\mathrm{p}=0.78$, CI: 0.50-2.49), physical abuse $(\mathrm{OR}=2.09, \mathrm{p}=$ 0.03 , CI: $1.09-3.99)$, emotional abuse $(\mathrm{OR}=2.71, \mathrm{p}=$ 0.002, CI: $1.44-5.09)$, neglect $(\mathrm{OR}=2.27, \mathrm{p}=0.02$, CI: $1.12-4.61)$ and violence within the family $(\mathrm{OR}=1.58, \mathrm{p}=$
0.18, CI: 0.81-3.06). Moreover, the SUD-specific risk factors did not differ significantly between the two groups: maternal use of alcohol during pregnancy $(\mathrm{OR}=1.96$, $\mathrm{p}=0.15, \mathrm{CI}: 0.79-4.87)$, parental alcohol use disorder $(\mathrm{OR}=1.03, \mathrm{p}=0.92, \mathrm{CI}: 0.53-2.02)$ and parental drug use disorder $(\mathrm{OR}=1.14, \mathrm{p}=0.82, \mathrm{CI}: 0.39-3.33)$. None of the mothers of the SUD + BPD patients consumed drugs during pregnancy; therefore, a statistical calculation is not possible.

\section{Discussion}

This is the first international multicenter study evaluating SUD and BPD risk factors among a large sample of treatment-seeking SUD patients with and without comorbid BPD using the same standardized interviews by trained clinicians. In the primary analysis, we included patients with other current comorbidities. The potential influence of co-occurring disorders (e.g. mood disorders, antisocial PD) was explicitly excluded in the secondary analysis by restricting the sample to patients with SUD only and BPD + SUD only. The results of both analyses were very similar, suggesting that they are generalizable to most clinical samples of treatment-seeking SUD patients with or without BPD. 
The first main finding was that patients with SUD + BPD had higher frequencies of physical and emotional neglect and abuse in childhood and were more likely to have a childhood history of family violence, irrespective of the presence of other psychiatric comorbidity, suggesting that increased childhood adversity is an independent risk factor for BPD in treatment-seeking SUD patients. For example, the risk of having experienced physical and emotional neglect was 2.8 times higher among SUD + BPD patients (45\%) than for SUD patients (19\%). As expected, the two groups did not differ in family history of SUD except that the mothers of the SUD + BPD patients were more likely to drink alcohol during pregnancy than the mothers of the SUD patients, suggesting an impact of alcohol on the unborn child might be associated with BPD. Alternatively, mothers of the SUD + BPD patients were more likely to drink alcohol during pregnancy because they were more impulsive and had problems to abstain from alcohol or at least to control drinking. However, this significance disappeared when the SUD-only group was compared with the BPD + SUD-only group. Thus, the impact of maternal alcohol use during pregnancy seemed to be more likely associated with the presence of other psychiatric comorbidities.

Our findings showed that the number of adverse childhood experiences was higher in SUD patients than in SUD + BPD patients. Nevertheless, the number of adverse childhood experiences does not seem to be a measure of the severity and repetition of traumatic events since severe childhood traumatic experiences were more frequent in SUD + BPD patients compared to SUD patients. It is rather a measure of the quantity of the different experiences. Unexpectedly, many SUD patients, either with or without BPD, reported not having been exposed to these risk factors. Other risk factors not assessed in this study such as underlying genetic vulnerability may also contribute to SUD and comorbid disorders.

The second main finding was that there were demographic differences between SUD and SUD + BPD patients. The two groups differed in gender; there were significantly more women with SUD + BPD comorbidity than men. This is consistent with findings from other non-SUD treatment settings showing higher rates of BPD among female patients than among male patients $[29,30]$. However, epidemiological studies of BPD based on data from a community sample have not found significant differences in gender, suggesting that gender differences in BPD are only true for patients ascertained in treatment settings, but not for those ascertained in the community $[8,31,32]$. In addition, SUD + BPD patients were younger than patients with SUD only. This result is consistent with studies reporting that BPD begins in adolescence, peaks in young adulthood and that most patients recover from BPD with time $[8,33]$. Moreover, patients with BPD may develop SUD at a younger age and develop a more severe SUD; therefore, it is possible that they seek treatment at a younger age. Further, when controlling for comorbidity with ADHD [22] and other comorbidities, the risk factors for BPD in SUD patients remain significant, suggesting that childhood abuse (except sexual abuse) and family violence are important risk factors for BPD in SUD patients.

When interpreting the findings, the following limitations should be taken into account. First, some of the risk factors assessed may be confounded. Physical abuse, for example, is associated with emotional abuse. Thus, it is difficult to disentangle these risk factors. Moreover, some BPD risk factors are missing in the IASP study (e.g. family history of impulsivity). Second, sensitive information such as adverse childhood experiences may be underreported. However, we have no reason to expect that underreporting would differ between the two groups. Third, we did not consider SUD as a risk factor for BPD or vice versa. For example, early substance use and heavy drinking in adolescence may promote the development of BPD by the negative impact of alcohol on the emotional regulation system. In contrast, twin analyses revealed that, at least in 14- to 18-years old adolescents, comorbidity between BPD traits and substance use is rather a consequence of common vulnerability and shared risk factors than due to one disease serving as a cause of the other [34]. Further prospective and longitudinal studies are needed to clarify the causal links between BPD and SUD. Fourth, while most of the data including the diagnoses were assessed using validated structured and standardized clinical interviews (e.g. SCID II, M.I.N.I. Plus 5.0.0, CAADID Interview for ADHD), risk factors were selfreported in the questionnaire part of the CAADID and are potentially subject to recall bias. In order to minimize recall bias in future research, longitudinal studies and external assessments are recommended. Moreover, it is important to use a more specific instrument such as the Childhood Trauma Questionnaire (CTQ) [35] and to include genetic vulnerability in further studies [34]. Fifth, in our study significantly more patients with SUD + BPD than with SUD also have ADHD. Because there is some overlap between the diagnostic criteria of BPD and $\mathrm{ADHD}$ (e.g. impulsivity), it is possible that patients were 
misdiagnosed with BPD and only had ADHD or vice versa. Finally, we did not have a BPD-only comparison group in the current study. As such, we were not able to evaluate the unique contribution of BPD specific risk factors.

\section{Conclusions}

As expected, there were no differences in the majority of risk factors for SUD between SUD patients with and without comorbid BPD. However, known risk factors for BPD such as childhood abuse and family violence were considerably more frequent in SUD patients with BPD, suggesting that childhood abuse and family violence were risk factors for BPD comorbidity among those suffering from SUDs. Thus, clinicians treating patients with both SUD and BPD should be aware of the elevated risk of experienced violence as a child and the need for targeted treatment strategies that consider this victimization.

\section{Acknowledgement}

We are grateful to all patients for their participation in this study. In Amsterdam, no external funding was obtained. The participating institute, Arkin, paid for the costs involved. At the Bergen Clinics Foundation in Norway, the main external funding was supplied by the Regional Research Council for Addiction in West Norway (Regionalt Kompetansesenter for Rusmiddelforskning i Helse Vest (KORFOR)), funding a 50\% position. The remaining resources, i.e. staff and infrastructure, was from the Bergen Clinics Foundation.

Norway, Fredrikstad: The IASP was funded by the Hospital, Sykehuset Østfold HF, not with money, but with $50 \%$ of the salary of the participants, then by two sources outside the hospital: The Regional Centre of Dual Diagnosis and the social - and Health directory.

Sweden, Stockholm: The study was funded by the Stockholm Centre for Dependency Disorders. Belgium: Funding of the IASPproject in Belgium: private funding.

France, Bordeaux: Research Grant PHRC (2006-2012) from the French Ministry of Health to M. Auriacombe and by a French National Research Agency PRA-CNRS-CHU-Bordeaux award (2008-2010) to M. Fatseas.

Spain, Barcelona: Financial support was received from Plan Nacional sobre Drogas, Ministerio de Sanidad y Política Social (PND 0080/2011), the Agència de Salut Pública de Barcelona and the Departament de Salut, Government of Catalonia, Spain.

Switzerland, Bern/Zurich: The IASP in Switzerland was funded by the Swiss Foundation of Alcohol Research (Grant \# 209).

Hungary, Budapest: There was no direct funding, but the following grant was used: The European Union and the European Social Fund have provided financial support to the project under the grant agreement no. TÁMOP 4.2.1./B-09/1/KMR-2010-0003.

Australia: The IASP Screening Phase was funded by a strategic funding faculty grant from the Curtin University of Technology, Perth, Western Australia.

USA, Syracuse: no funding was obtained.

\section{References}

1 Maniglio R: The role of child sexual abuse in the etiology of substance-related disorders. J Addict Dis 2011;30:216-228.

2 Hasin D, Fenton MC, Skodol A, Krueger R, Keyes K, Geier T, Greenstein E, Blanco C, Grant B: Personality disorders and the 3-year course of alcohol, drug, and nicotine use disorders. Arch Gen Psychiatry 2011;68:1158-1167.

3 Kranzler HR, Rounsaville BJ: Dual Diagnosis and Psychiatric Treatment: Substance Abuse and Comorbid Disorders, ed 2. New York, Dekker, 2004.

4 Trull TJ, Sher KJ, Minks-Brown C, Durbin J, Burr R: Borderline personality disorder and substance use disorders: a review and integration. Clin Psychol Rev 2000;20:235-253.

5 Leichsenring F, Leibing E, Kruse J, New AS, Leweke F: Borderline personality disorder. Lancet 2011;377:74-84.

6 Sher KJ, Trull TJ: Substance use disorder and personality disorder. Curr Psychiatry Rep 2002;4:25-29.

7 Trull TJ, Jahng S, Tomko RL, Wood PK, Sher KJ: Revised NESARC personality disorder diagnoses: gender, prevalence, and comorbidity with substance dependence disorders. J Pers Disord 2010;24:412-426.
8 Tomko RL, Trull TJ, Wood PK, Sher KJ: Characteristics of borderline personality disorder in a community sample: comorbidity, treatment utilization, and general functioning. J Pers Disord 2014;28:734-750.

9 Zanarini MC, Frankenburg FR, Weingeroff JL, Reich DB, Fitzmaurice GM, Weiss RD: The course of substance use disorders in patients with borderline personality disorder and Axis II comparison subjects: a 10-year follow-up study. Addiction 2011;106:342-348.

10 Verheul R: Co-morbidity of personality disorders in individuals with substance use disorders. Eur Psychiatry 2001;16:274-282.

11 Morgenstern J, Langenbucher J, Labouvie E, Miller KJ: The comorbidity of alcoholism and personality disorders in a clinical population: prevalence rates and relation to alcohol typology variables. J Abnorm Psychol 1997;106: 74-84.

12 Kraemer HC, Kazdin AE, Offord DR, Kessler RC, Jensen PS, Kupfer DJ: Coming to terms with the terms of risk. Arch Gen Psychiatry 1997;54:337-343.

13 Kilpatrick DG, Acierno R, Saunders B, Resnick HS, Best CL, Schnurr PP: Risk factors for adolescent substance abuse and dependence: data from a national sample. J Consult Clin Psych 2000;68:19-30.

14 Hemphill SA, Heerde JA, Herrenkohl TI, Patton GC, Toumbourou JW, Catalano RF: Risk and protective factors for adolescent substance use in Washington State, the United States and Victoria, Australia: a longitudinal study. J Adolesc Health 2011;49:312-320.

15 Dube SR, Felitti VJ, Dong M, Chapman DP, Giles WH, Anda RF: Childhood abuse, neglect, and household dysfunction and the risk of illicit drug use: the adverse childhood experiences study. Pediatrics 2003;111:564572

16 Distel MA, Trull TJ, de Moor MM, Vink JM, Geels LM, van Beek JH, Bartels M, Willemsen G, Thiery E, Derom CA, Neale MC, Boomsma DI: Borderline personality traits and substance use: genetic factors underlie the association with smoking and ever use of cannabis, but not with high alcohol consumption. J Pers Disord 2012;26:867-879.

17 Hernandez A, Arntz A, Gaviria AM, Labad A, Gutierrez-Zotes JA: Relationships between childhood maltreatment, parenting style, and borderline personality disorder criteria. J Pers Disord 2012;26:727-736. 
18 Bradley R, Jenei J, Westen D: Etiology of borderline personality disorder: disentangling the contributions of intercorrelated antecedents. J Nerv Ment Dis 2005;193:24-31.

19 Chanen AM, Kaess M: Developmental pathways to borderline personality disorder. Curr Psychiatry Rep 2012;14:45-53.

20 Hawkins JD, Catalano RF, Miller JY: Risk and protective factors for alcohol and other drug problems in adolescence and early adulthood: implications for substance abuse prevention. Psychol Bull 1992;112:64-105.

21 Widiger TA, Trull TJ: Borderline and narcissistic personality disorders; in Sutker P, Adams H (eds): Comprehensive Textbook of Psychopathology. New York, Plenum, 1993, pp 371-394.

22 van Emmerik-van Oortmerssen $\mathrm{K}$, van de Glind G, Koeter MW, Allsop S, Auriacombe M, Barta C, Bu ET, Burren Y, Carpentier PJ, Carruthers S, Casas M, Demetrovics Z, Dom G, Faraone SV, Fatseas M, Franck J, Johnson B, Kapitany-Foveny M, Kaye S, Konstenius M, Levin FR, Moggi F, Moller M, RamosQuiroga JA, Schillinger A, Skutle A, Verspreet $S$, van den Brink W, Schoevers RA: Psychiatric comorbidity in treatment seeking substance use disorder patients with and without ADHD: Results of the IASP study. Addiction 2014;109:262-272.

23 ICASA. 2014. http://www.adhdandsubstance abuse.org.

24 van de Glind G, Van Emmerik-van Oortmerssen K, Carpentier PJ, Levin FR, Koeter MW, Barta C, Kaye S, Skutle A, Franck J, Kon- stenius M, Bu ET, Moggi F, Dom G, Demetrovics $Z$, Fatseas $M$, Schillinger A, KapitanyFoveny M, Verspreet S, Seitz A, Johnson B, Faraone SV, Ramos-Quiroga JA, Allsop S, Carruthers S, Schoevers RA, van den Brink W: The International ADHD in Substance Use Disorders Prevalence (IASP) study: background, methods and study population. Int J Meth Psych Res 2013;22:232-244.

25 Williams JB, Gibbon M, First MB, Spitzer RL, Davies M, Borus J, Howes MJ, Kane J, Pope HG Jr, Rounsaville B, et al: The structured clinical interview for DSM-III-R (SCID). II. Multisite test-retest reliability. Arch Gen Psychiatry 1992;49:630-636.

26 Spitzer RL, Williams JB, Gibbon M, First MB: The structured clinical interview for DSMIII-R (SCID). I: history, rationale, and description. Arch Gen Psychiatry 1992;49:624629.

27 Sheehan DV, Lecrubier Y, Sheehan KH, Amorim P, Janavs J, Weiller E, Hergueta T, Baker R, Dunbar GC: The Mini-International Neuropsychiatric Interview (M.I.N.I.): the development and validation of a structured diagnostic psychiatric interview for DSM-IV and ICD-10. J Clin Psychiatry 1998;59(suppl 20):22-33.

28 Epstein JN, Johnson D, Conners CK: Conners Adult ADHD Diagnostic Interview for DSMIV Technical Manual. North Towanda, Multihealth Systems, 2001.

29 Widiger TA, Weissman MM: Epidemiology of borderline personality disorder. Hosp Community Psychiatry 1991;42:1015-1021.
30 Bernardi S, Faraone SV, Cortese S, Kerridge BT, Pallanti S, Wang S, Blanco C: The lifetime impact of attention deficit hyperactivity disorder: results from the National Epidemiologic Survey on Alcohol and Related Conditions (NESARC). Psychol Med 2012;42:875-887.

31 Zanarini MC, Horwood J, Wolke D, Waylen A, Fitzmaurice G, Grant BF: Prevalence of DSM-IV borderline personality disorder in two community samples: 6,330 English 11-year-olds and 34,653 American adults. J Pers Disord 2011;25:607-619.

32 Grant BF, Chou SP, Goldstein RB, Huang B, Stinson FS, Saha TD, Smith SM, Dawson DA, Pulay AJ, Pickering RP, Ruan WJ: Prevalence, correlates, disability, and comorbidity of DSM-IV borderline personality disorder: results from the Wave 2 National Epidemiologic Survey on Alcohol and Related Conditions. J Clin Psychiatry 2008;69:533-545.

33 Paris J: The treatment of borderline personality disorder: implications of research on diagnosis, etiology, and outcome. Annu Rev Clin Psychol 2009;5:277-290.

34 Bornovalova MA, Hicks BM, Iacono WG McGue M: Longitudinal twin study of borderline personality disorder traits and substance use in adolescence: developmental change, reciprocal effects, and genetic and environmental influences. Personal Disord 2013;4:23-32.

35 Bernstein DP, Fink L: Childhood Trauma Questionnaire: A Retrospective Self-Report Manual. San Antonio, The Psychological Corporation, 1998. 